\title{
An investigation of heat transfer coefficient during refrigerants condensation in vertical pipe minichannels
}

\author{
Tadeusz Bohdal ${ }^{1}$, Henryk Charun $^{1}$, Marcin Kruzel $^{1, *}$, and Matgorzata Sikora ${ }^{1}$ \\ ${ }^{1}$ Koszalin University of Technology, Department of Energetics, ul. Racławicka 15-17, PL - 75-620 Koszalin, Poland
}

\begin{abstract}
This article presents the results of experimental research of heat transfer coefficient in air cooled vertical pipe minichannels during R404A, R407C and R410A high-pressure refrigerants condensation. The study determined local and average heat transfer coefficient values in full range of vapour quality, $x=0 \div 1$. On the basis of experimental investigations, the dependence of heat transfer on the vapour quality $x$, mass flux density $G$ and minichannel's internal diameter $d_{w}$ was obtained.
\end{abstract}

\section{Introduction}

The dynamic expansion in global development forces the unceasing need for innovative solutions in design and construction of equipment. These solutions aim at intensifying utility parameters such as power, efficiency and reducing their size while lowering production costs [1]. Researchers are therefore looking for the best solutions from a technical and economic point of view. Increase of efficiency factor results in considerable usage of equipment and that generates increase in production costs [3]. One of the main causes of wear is the inefficient cooling. Due to the limited size of conventional HE's, micro- condensers fits perfectly into the needs of the market. But we still have to be aware of ecological considerations. The smaller the size of the system, the less risk to the environment - in case of leak of the refrigerant to the environment.

Small refrigeration systems are commonly used, for example, in personal computers or smartphones. However, miniature heat exchangers will be gradually displaced on the market by "micro" heat exchangers [2]. Growing demands and requirements for heat exchangers constructors forces new solutions. The authors assume that the efficiency of the micro heat exchangers is mostly influenced by: the nature of the refrigerant flow, the type of refrigerant used, and the influence of the surface tension forces. Not meaningless stays the type of heat reception and channels orientation.

There is still a small number of heat exchangers designed with an air-cooled microchannels. A similar situation occurs with vertical channels.

The article [19] describes study on HTC in horizontal rectangular multiport minichannel with and without fins using R134a. Authors fabricated a new experimental apparatus in order to obtain explicit local condensation heat transfer coefficient measurements over a range of test conditions. The test section was an $852 \mathrm{~mm}$ long horizontal rectangular multiport minichannel with and without fins having 20 channels with a hydraulic diameter of $0.64 \mathrm{~mm}$ and $0.81 \mathrm{~mm}$. The measurements were done over a range of saturation temperature from 30 to $35{ }^{\circ} \mathrm{C}$ with mass fluxes ranging from 50 to 200 $\mathrm{kg} \cdot \mathrm{m}^{-2} \cdot \mathrm{s}^{-1}$. The effects of vapour quality, mass fluxes, channel geometry, and saturation temperature on the heat transfer coefficient have been clarified and analyzed. The experimental results were compared with the wellknown condensation heat transfer models available in the open literature. All of the existing correlations were failed to capture the present experimental heat transfer coefficient with a high degree of accuracy. As a consequence, a new condensation heat transfer correlation was developed based on the present experimental data and validated with 750 data points collected from the available journal.

Article by Chen et. al. [2] describes FC-72 refrigerant's condensation model in rectangular channel with hydraulic diameter $d_{h}=1 \mathrm{~mm}$. The model was confronted with research results available in the world literature. It has been noted that the vapor velocity of the medium is significantly higher than that of its condensate. There was also found that an increase in the size of the bubbles goes along with the increase in the mass flux density.

An experimental investigation was carried out in paper [20] for the benefit of refrigerant mass flux, local vapor quality, coolant flow rate and inlet coolant temperature on the local condensation heat transfer coefficient. Flow visualization was also carried out during the flow of condensation using a high-speed camera integrated with a microscope. HFE-7100, a dielectric and eco-friendly refrigerant was used in rectangular multimicrochannels with a hydraulic diameter of $0.57 \mathrm{~mm}$. Experiments were performed at a saturation temperature of $60{ }^{\circ} \mathrm{C}$, mass flux range 48-126 $\mathrm{kg} /(\mathrm{m} 2 \mathrm{~s})$, coolant flow rate range 0.5-1.1 L / min and

Corresponding author: marcin.kruzel@tu.koszalin.pl 
inlet coolant temperature range $20-40{ }^{\circ} \mathrm{C}$. The results showed that the local condensation heat transfer coefficient increases with increasing mass flux and decreases with decreasing local vapor quality. A negligible effect of the coolant side conditions, saturation-to-wall temperature difference, on the local condensation heat transfer coefficient was found. The main flow regime was an annular flow, while slug and bubbly flow were found at some operating conditions. The experimental results were correlated for heat transfer rates. also, two existing flow pattern maps, for conventional and mini / microchannels, were used to compare the current flow pattern results.

In paper [21], the successive evaporation and condensation of water-ethanol and water-methanol liquid film mixtures for cooling purpose was investigated. The simulations were achieved using a finite difference model to describe the heat and mass transfer during this process. The studied process relied on the absorption of energy at the evaporator and then the release of this energy at the condenser. The evaporation and heat exchange abilities of the mixtures composition ware analysed to identify the appropriate mixture for the new proposed cooling approach. The results indicated that more energy equilibrium occurs with high concentration of water in the mixture with the advantage of having low bulk and interface temperature.

A new, universal approach to predict the heat transfer coefficient in minichannels and microchannels were presented by Kim and Mudawar [5]. The concept applies to a number of fluids with significantly different thermophysical properties, as well as for variable channel geometry and flow parameters. The authors collected a database of 28 different sources, including over 4000 measurement points. The data concern condensation of 17 types of working fluids in single channels and multiports, and their hydraulic diameters are in the range: $d_{h}=0.424-6.22 \mathrm{~mm}$. Mass flux density $\mathrm{G}=53-1403 \mathrm{~kg} \cdot \mathrm{m}^{-2} \cdot \mathrm{s}^{-1}$. Two new correlations were proposed: the first for the annular flow, the second for plug flow and bubbly flow.

Fronk and Garimella [4] investigated the heat transfer coefficient and pressure drop during carbon dioxide (CO2) condensation in rectangular minichannels. The channels hydraulic diameters were $\mathrm{d}_{\mathrm{h}}=0.1 \mathrm{~mm}$ and 0.16 $\mathrm{mm}$. Channels were made of copper by electroforming. Thermo-flow parameters were measured at mass flux density $\mathrm{G}=400,600$ and $800 \mathrm{~kg} \cdot \mathrm{m}^{-2} \cdot \mathrm{s}^{-1}$ and the full range of refrigerant's vapor quality $\mathrm{x}$. Authors compared the results with the investigations data from several existing correlations. The best agreement for was obtained with Garimella correlation [5]. For the heat transfer coefficient, the best agreement was for authors $[6,7,8,9]$ data.

\section{Subject of research}

The subject of the research were vertical pipe minchannels, made of stainless steel with an inner diameter $\mathrm{d}_{\mathrm{w}}=0.5 \div 2.5 \mathrm{~mm}$ and length $\mathrm{L}=1000 \mathrm{~mm}$. The refrigerants R404A, R407C and R410A were used for the tests. The section of the minichannel was cooled with air at a flow velocity of $=17 \mathrm{~m} \cdot \mathrm{s}^{-1}$, and the refrigerant was supplied with set and timed thermal and flow parameters. Minichannels were placed in an air channel measuring $60 \times 120 \mathrm{~mm}$. Experimental research has been carried out in the following range of thermal and flow parameters:.

Table 1. Range of parameters.

\begin{tabular}{|c|c|}
\hline Parameter & Range \\
\hline $\begin{array}{c}\text { mass flux } \\
\text { density }\end{array}$ & $\begin{array}{c}\mathrm{G}=50 \div 200 \\
\mathrm{~kg} \cdot \mathrm{m}^{-2} \cdot \mathrm{s}^{-1}\end{array}$ \\
\hline $\begin{array}{c}\text { heat flux } \\
\text { density }\end{array}$ & $\mathrm{q}=0 \div 10$ \\
\hline $\begin{array}{c}\text { vapor } \\
\text { quality }\end{array}$ & $\mathrm{x}=0 \div 1$ \\
\hline $\begin{array}{c}\text { saturation } \\
\text { temperature }\end{array}$ & $\mathrm{t}_{\mathrm{s}}=20 \div 40{ }^{\circ} \mathrm{C}$ \\
\hline
\end{tabular}

The construction of the experimental facility enabled the measurement of the temperature and pressure of the refrigerant, the temperature of the channel wall and cooling air over the length of the measuring section. The flow rate of the refrigerant and coolant were also measured.

\section{Experimental facility}

The main element of the test stand was the tube minichannel with an internal diameter $d_{\mathrm{w}}$ and an overall length of $1000 \mathrm{~mm}$ (on the active length of $950 \mathrm{~mm}$, the heat transfer coefficient was measured).

Figure 1 shows the actual view of the measurement facility, while in Figure 2 the schematic diagram of the facility.

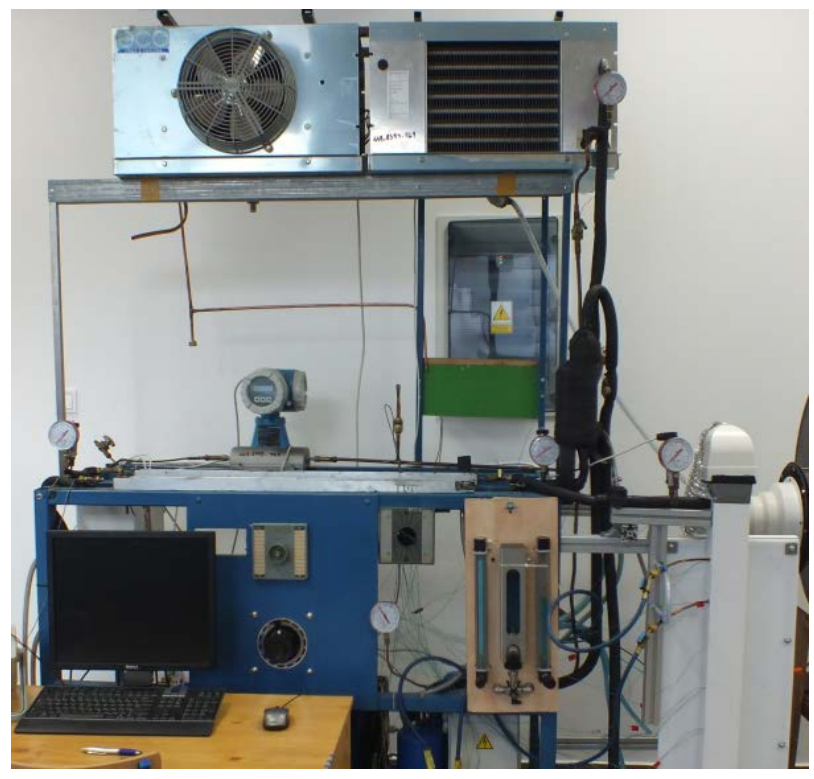

Fig. 1. Overall view of test stand.

The refrigerant condensation process during refrigerants flow took place in pipe minichannels. The superheated vapour of the refrigerant was directed by a control valve 
to the measuring section after compressing in the reciprocating compressor.

A water-cooled heat exchanger was installed before the refrigerant at the inlet of the measuring section. On the basis of the thermal balance of the exchanger, the vapour quality was calculated. Exchanger received the heat of overheated refrigerant. The intensity of heat transfer was controlled by the change of the water flow rate cooling the exchanger. So parameterized refrigerant vapour supplied the measuring section.

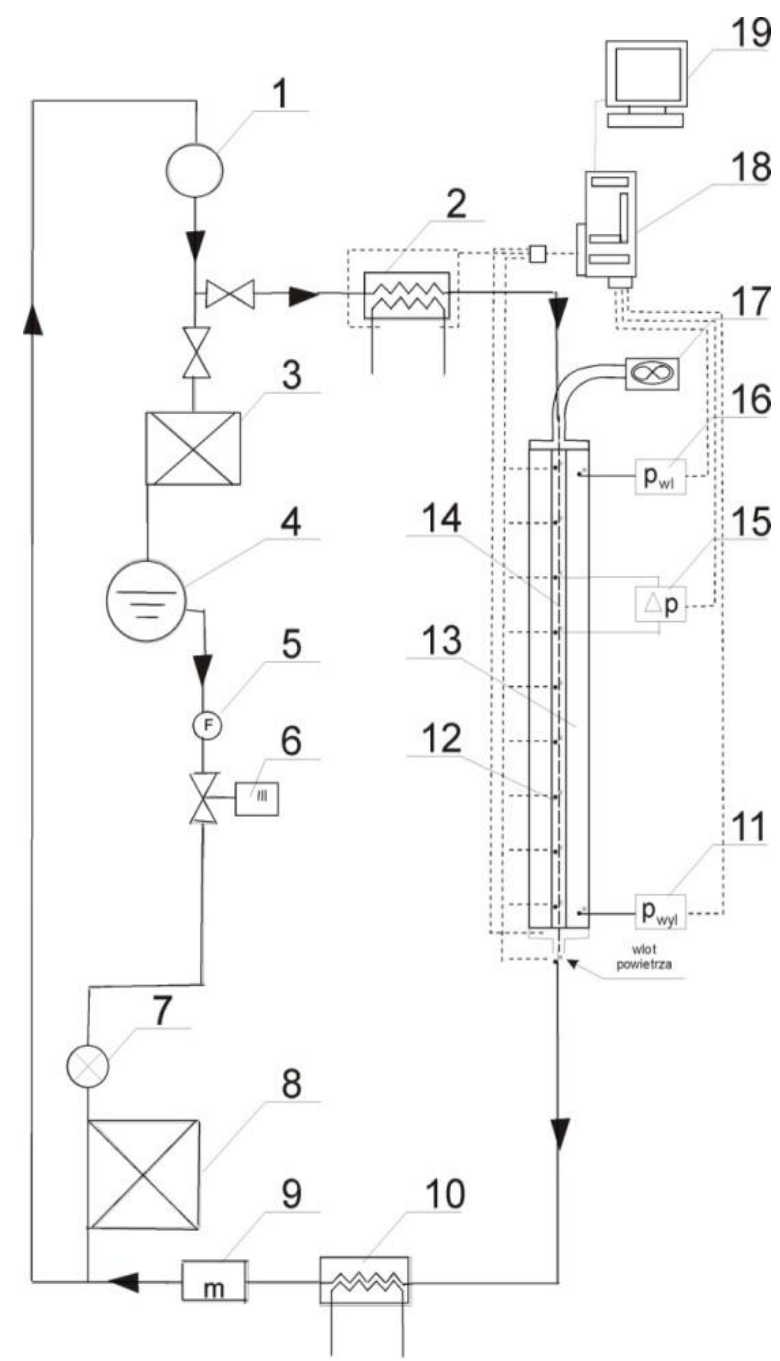

Fig. 2. Schematic diagram of test stand: 1) compressor, 2) pre heat exchanger, 3) condenser, 4) refrigerant liquid tank, 5) filter, 6) electromagnetic valve, 7) expansion valve, 8) fan refrigerator, 9) refrigerant mass flow meter, 10) heat exchanger, 11) inlet pressure sensor, 12) thermocouples, 13) air channel, 14) pipe minichannel, 15) differential pressure measurement, 16) outlet pressure sensor, 17) fan, 18) data acquisition system, 19) computer.

\section{Test results}

Condensation process analysis requires the acquaintance of the distribution of local heat transfer coefficient values at L length of the refrigerant flow. Figure 3 shows the dependence of the local heat transfer coefficient $\alpha_{x}$ on the change of mass flux density $\mathrm{G}$ for inner diameter $\mathrm{d}_{\mathrm{w}}=0,5 \mathrm{~mm}$.

a)

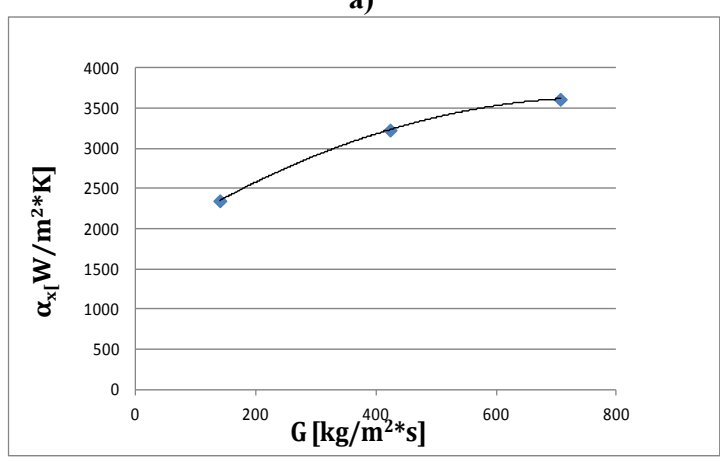

b)

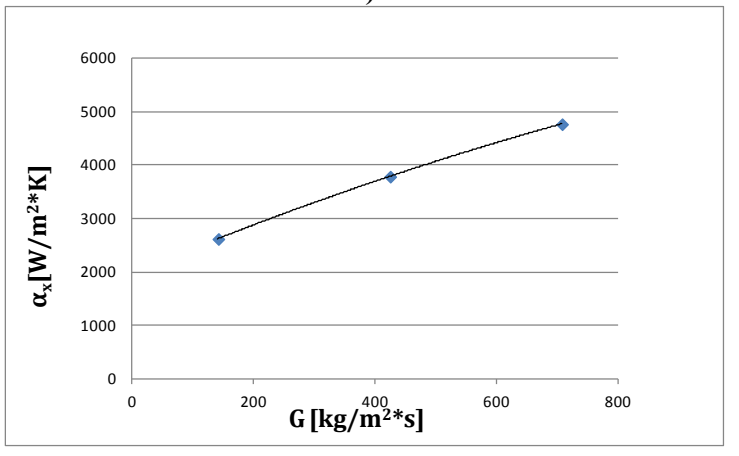

Fig. 3. Experimental investigation results of local heat transfer coefficient during condensation of a) R410A, b) R404A refrigerants in vertical pipe minichannel with internal diameter $\mathrm{d}=0.5 \mathrm{~mm}$.

As it is shown on figure 3 the local heat transfer values increases along with the mass flux density $G$ rises. A similar relationship occurs for both examined refrigerants. Figure 4 shows the dependence of local heat transfer values on the inner diameter $d_{w}$.

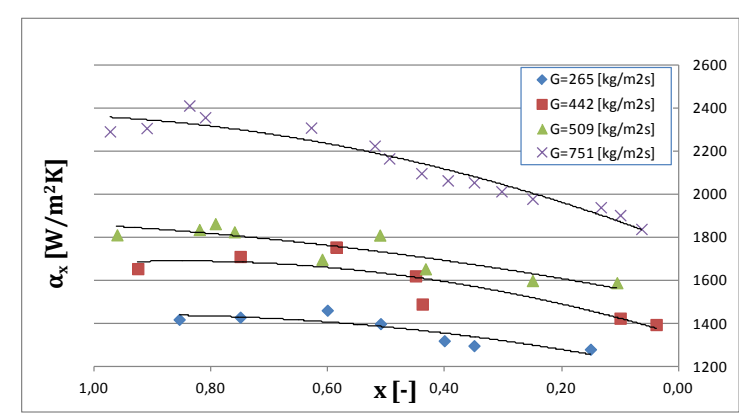

Fig. 4. Experimental investigation results of local heat transfer coefficient dependence on vapour quality $\mathrm{x}$ during R404A condensation in pipe minichanel with $\mathrm{d}_{\mathrm{w}}=2.0 \mathrm{~mm}$ inner diameter.

The dependence of local heat transfer coefficient on vapour quality is presented on figure 4 . The increase of vapour quality $\mathrm{x}$ results in HTC values increase. Highest values were noticed for $x=(0.6 \div 0.9)$ which is the proper condensing area, in which the heat transfer is most efficient. 


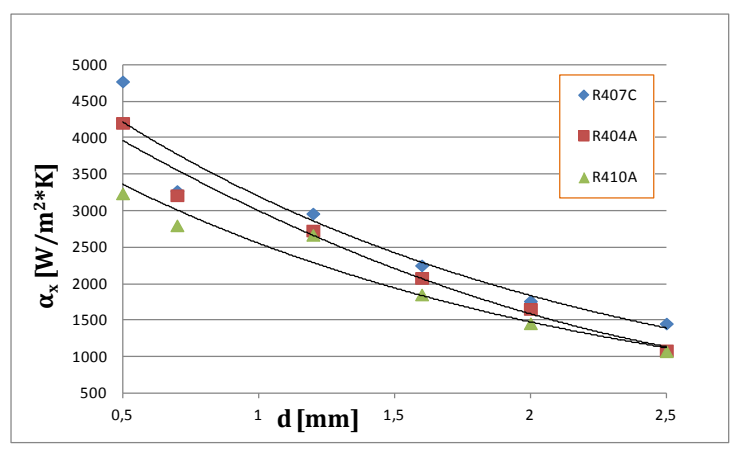

Fig. 5. Experimental investigation results of local heat transfer coefficient dependence on inner diameter during condensation of all three examined refrigerants.

Figure 5 shows that efficiency of heat transfer depends on the size of the inner diameter $d_{w}$. Values of local heat transfer coefficient rise with the reduction of inner diameter. Highest HTC values were noticed during condensation of $\mathrm{R} 407 \mathrm{C}$ refrigerant in $\mathrm{d}_{\mathrm{w}}=0.5 \mathrm{~mm}$ wide minichannel. A similar trend for all examined refrigerants.

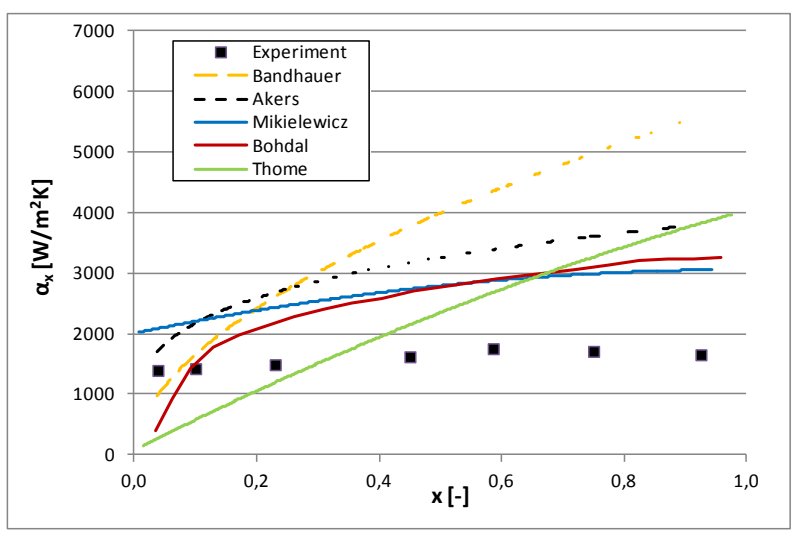

Fig. 6. Experimental investigation results of local heat transfer coefficient during condensation of a) R410A, b) R404A refrigerants in vertical pipe minichannel with internal diameter $\mathrm{d}=0.5 \mathrm{~mm}$

The results of own empirical studies were compared with the results of calculations according to the correlations of other authors [10-14].

The graphical comparison shows the adjustment of existing heat exchange prediction models to the results of the experiment.

Figure 6 shows that the results of calculations according to the analyzed models do not fit into the course of the experiment results. A different course of calculation results may be caused by different (much lower) values of heat flow $q$ that characterize heat exchange in aircooled condensers. The calculations indicated best agreement with experimental results for Thome's correlation (figure 7).

But the results were not satisfactory. Mean absolute percentage error MAPE was 32\% for R404A, 35\% for $\mathrm{R} 407 \mathrm{C}$ and $47 \%$ for R410A. The results of the comparison with the correlations according to the other authors were subject to a significant error (MAPE) of more than $50 \%$. Such a large discrepancy may result from different ranges of applicability of particular correlations.

a)

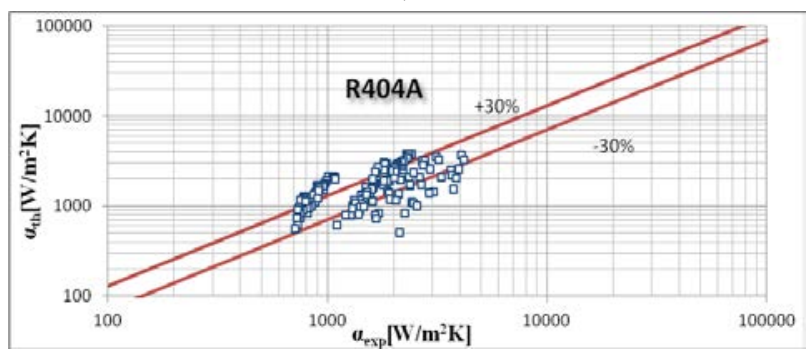

b)

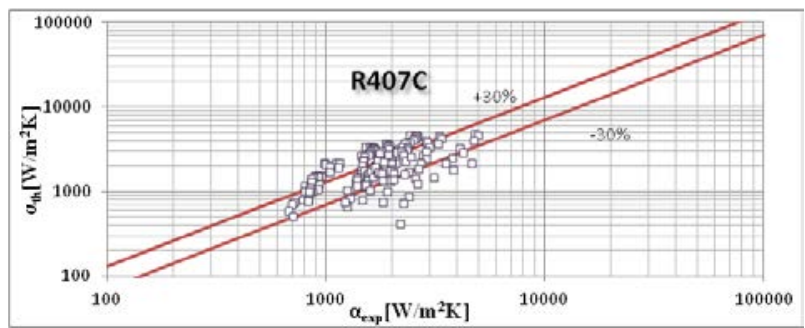

c)

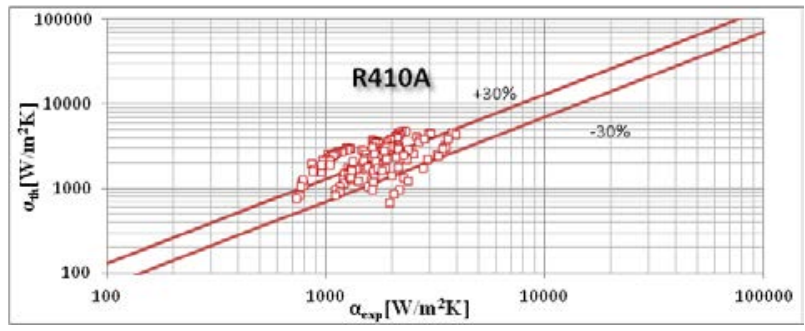

Fig. 7. Comparison of experimental data of the local heat transfer coefficient with the results of calculations according to the Thome's model for a) R404A, b) R407C and c) R410A refrigerants condensation.

Heat exchange during the refrigerants two-phase flow through a minichannel is a very complicated process. Therefore, quantifying this process should be considered both the nature of the refrigerant flow and its properties. With this in mind, a model was new model was developed. The model is intended for prediction of heat transfer coefficient values in a vertical air-cooled minichannels. Based on the analysis of the results of own experimental research data of R407C, R410A and $\mathrm{R} 404 \mathrm{~A}$ refrigerants condensation process in minichanels, correlation of various authors and dimensional analysis a new correlation for local heat transfer coefficient and local pressure drop was obtained. Correlation parameters were determined using nonlinear regression model [18] estimated by Levenberg - Marquardt method (in Statistica's standard pacage).

Local heat transfer coefficient $\alpha_{x}$. was calculated by:

$$
\begin{gathered}
N u_{x}=0.63 \cdot R e_{l}^{0.35} \cdot p_{r}^{-0.49} \cdot P r_{l}^{0.79} \cdot\left(\frac{x}{1-x}\right)^{0.22} \\
\alpha_{x}=\frac{N u \cdot \lambda_{l}}{d_{w}}
\end{gathered}
$$


The usefulness of the above correlation was confirmed experimentally in the field of operation of air-cooled minichannels, i.e. for low values of heat flux density $\mathrm{q}=$ $=500 \div 5000 \mathrm{~W} \cdot \mathrm{m}^{-2}$.

In order to verify the scope of applicability of the existing model describing heat exchange during refrigerants condensation in mini- and microchannels, the method of residual analysis using the error MAPE (mean absolute percentage error) was applied:

$$
M A P E=\frac{1}{n} \sum_{i=1}^{n}\left[\frac{\left|N u_{t h}-N u_{e x p}\right|}{N u_{\text {exp }}}\right] \cdot 100 \%
$$

$N u_{t h}$ means the result of calculations according to the correlation of individual authors, whereas $N u_{\exp }$ is the value of a given quantity determined experimentally, $n$ - is the number of measurements made. MAPE shows the average error that should be expected when anticipating the behavior of a given model in subsequent studies.

In the case of the Nusselt number, the MAPEs were calculated for the Thome [12], Akers [13], Bandhauer [14], Shah [15], Tang [16], and Cavallini [] models. The results were compared with the author's correlation (Table 2).

Table 2. Comparison of HTC prediction model MAPE for $\mathrm{R} 407 \mathrm{C}$ refrigeration.

\begin{tabular}{|cccccccc|}
\hline \multicolumn{7}{|c|}{ MAPE \% } \\
\hline $\begin{array}{c}\boldsymbol{d}_{\boldsymbol{w}} \\
{[\mathbf{m m} \boldsymbol{m}]}\end{array}$ & Thome & Akers & Shah & Tang & Bandhauer & Cavallini & autor \\
\hline $\mathbf{2 , 5}$ & 55 & 190 & 498 & 601 & 152 & 147 & $\mathbf{1 1}$ \\
\hline $\mathbf{2}$ & 43 & 158 & 399 & 408 & 135 & 78 & $\mathbf{6}$ \\
\hline $\mathbf{1 , 6}$ & 26 & 131 & 264 & 334 & 113 & 83 & $\mathbf{6}$ \\
\hline $\mathbf{1 , 2}$ & 21 & 83 & 198 & 185 & 99 & 64 & $\mathbf{8}$ \\
\hline $\mathbf{0 , 7}$ & 25 & 61 & 162 & 111 & 85 & 68 & $\mathbf{5}$ \\
\hline $\mathbf{0 , 5}$ & 41 & 33 & 99 & 96 & 58 & 71 & $\mathbf{1 0}$ \\
\hline $\begin{array}{c}\text { Mean } \\
\text { value }\end{array}$ & $\mathbf{3 5}$ & $\mathbf{1 0 9}$ & $\mathbf{2 7 0}$ & $\mathbf{2 8 9}$ & $\mathbf{1 0 7}$ & $\mathbf{8 5}$ & $\mathbf{8}$ \\
\hline
\end{tabular}

Figure 8 contains a quantitative graphic comparison for MAPE errors of particular correlations included in the study.

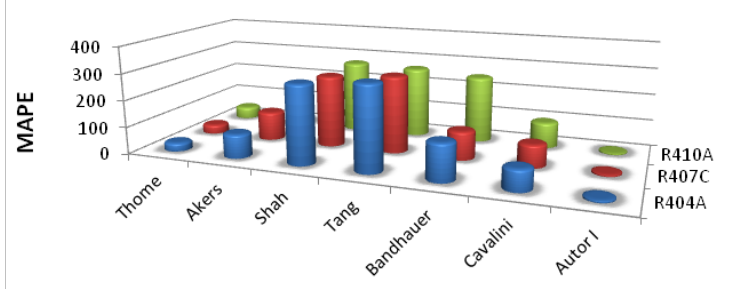

Fig. 8. Comparison of MAPE errors for the calculation of the local Nusselt number according to different $\mathrm{Nu}_{\mathrm{th}}$ authors with the results of experimental $\mathrm{Nu}_{\text {exp }}$.

The results of the local Nusselt number comparison for all examined internal diameters are presented below. Figure 9 shows the diffrences bettween theoretical and experimental results. for condensation in vertical pipe minichannel.

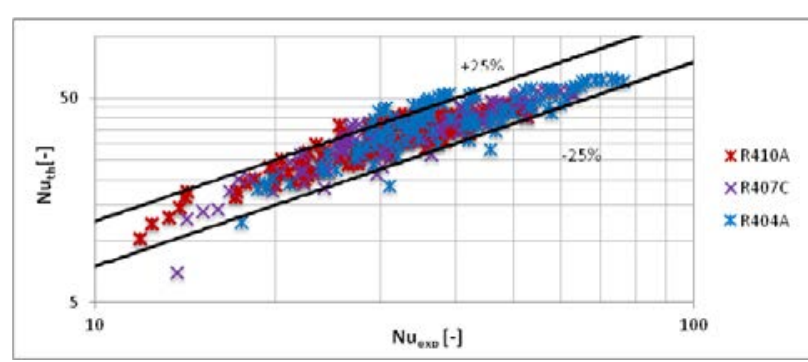

Fig. 9. Comparison of experimental results with the results of calculations according to the authors model (1) for the local Nusselt number.

Discrepancies between experimental values and calculated values are within $\pm 25 \%$. The correlation describes the results of experimental studies with an average percentage error of $8 \%$. For a two-phase flow, this result was considered satisfactory.

\section{Conclusions}

1) Efficiency of heat transfer increases along with increasing mass flux density $G$ of the refrigerant in the minichannel.

2) Local values of the heat transfer coefficient $\alpha_{x}$ increases with the increase in the vapor quality $x$ of the refrigerant, in the range of about $x=0 \div 0.8$, and then decrease slightly.

3) Correlations currently available in literature describe the heat transfer during condensation in small diameter water cooled minichannels. They do not have unfortunately analogous use in the case of condensation in air-cooled minichannels. The condensation process in air-cooled minichannel runs at significantly lower heat flux density values.

4) Appliance of existing correlations describing condensation in water-cooled minichannels used for aircooling was considered unsatisfactory, because the experiment's discrepancy range is greater than $\pm 50 \%$ for heat exchange.

5) To calculate the local values of heat transfer coefficient during refrigerants condensation in air cooled minichannels (for low heat flux densities $q=500$ $\div 5000 \mathrm{~W} \cdot \mathrm{m}^{-2}$ it is proposed to use dependencies determined on the basis of author's experimental investigations according to the dependence (1).

\section{Nomenclature}

\section{Symbols}

$\alpha_{\mathrm{x}} \quad-$ local heat transfer coefficient, $\left[\mathrm{W} \cdot \mathrm{m}^{-2} \cdot \mathrm{K}^{-1}\right.$ ]

$\mathrm{d}_{\mathrm{w}} \quad-\quad$ internal diameter, [mm]

$\mathrm{d}_{\mathrm{h}} \quad-$ hydraulic diameter, $[\mathrm{mm}]$

$\mathrm{G} \quad-\quad$ mass flux density, $\mathrm{kg} /\left[\mathrm{m}^{2} \cdot \mathrm{s}\right]$,

$p_{\mathrm{r}} \quad-\quad$ reduced pressure [-]

$p_{s} \quad-\quad$ saturation pressure $[\mathrm{kPa}]$

$p_{k} \quad-\quad$ critical pressure $[\mathrm{kPa}]$

$q \quad-$ heat flux, $\left[\mathrm{kW} \cdot \mathrm{m}^{-2}\right]$

$v \quad-$ velocity $\left[\mathrm{m} \cdot \mathrm{s}^{-1}\right]$ 


\section{Acronyms}

$\mathrm{HE} \quad-$ Heat Exchanger

HTC - Heat Transfer Coefficient

MAPE - Mean Absolute Percentage Error

\section{References}

1. T. Bohdal, M. Kruzel, M. Sikora, Journal of Mechanical and Energy Engineering, vol. 1(41), no. 2. (2017).

2. A. H. Al-Zaidi, M. M. Mahmoud, T. G. Karayiannis, Experimental Thermal and Fluid Science 90 (2018) 153-173.

3. M. Kruzel, Wydawnictwo Uczelniane Politechniki Koszalińskiej, (2012) 95-104.

4. M. B. Fronk, S. Garimella: Internationoal Journal of Heat and Mass Transfer 100 (2016) 150-164.

5. S.M. Kim, I. Mudawar, International Journal of Heat and Mass Transfer Vol. 55 (11-12). - 2012. 32463261 .

6. A. Agarwal, T.M. Bandhauer, S. Garimella, Int. J. Refrig. 33 (6) (2010) 1169-1179.

7. M.K. Dobson, J.C. Chato, Condensation in smooth horizontal tubes, J. Heat Transfer 120 (1) (1998) 193-213.

8. W. W. Wang, T.D. Radcliff, R.N. Christensen, Exp. Thermal Fluid Sci. 26 (5) (2002) 473-485.

9. D.P. Traviss, W.M. Rohsenow, A.B. Baron, ASHRAE Trans. 79 (Part 1) (1973) 157-165.
10. T. Bohdal, H. Charun, M. Sikora, International Journal of Refrigeration, vol. 59. - 2015, pp. 210223.

11. D. Mikielewicz, Heat Transfer Engineering, Taylor \& Francis, 2016, pp. 1158-1171.

12. J.R. Thome, J. El Hajal, A. Cavallini, Int. J. Heat Mass Transf. 46, (2003), 3365-3387.

13. W. W. Akers, H. F. Rosson, Chemical Eng. Progr. Symposium 1960, Series 50. - 1960, pp. 145-149.

14. T.M. Bandhauer, S. Agarwal, S. Garimella J. Heat Transfer, vol. 128, (2006), 1050-1059.

15. M.M. Shah, Int. Journal of Refrigeration 67 (2016), $22-41$.

16. L.Tang Ph.D., College Park, MD University of Maryland, (1997).

17. A. Cavallini, G. Censi, D. Del Col, L. Doretti, A. Longo, A. Rossetto, Heat Transfer Eng. 27 (8), (2006), pp. 31-38.

18. M. Dobosz, Akademicka Oficyna Wydawnicza EXIT, Warszawa (2003), 233-276.

19. M. Mostaqur Rahman, K. Kariya, A. Miyara, Int. Journal of Heat and Mass Transfer 116, (2018), pp. 50-60.

20. Ali H. Al-Zaidia, M.M. Mahmouda, T.G. Karayianniss, Experimental Thermal and Fluid Science, 90, (2018), pp. 153-173.

21. M. Najim, M. Feddaoui, A. Nait Alla, A. Charef, A.E. Kabeel, International Journal of Heat and Mass Transfer 122, (2018), pp. 895-912. 